\title{
SHADE MATCHING OF CAD/CAM LITHIUM SILICATE CERAMICS VENEERED ON NEWLY INTRODUCED FOUNDATION MATERIAL
}

\author{
Nahla Gamal Eldin Elhelbawy*
}

\begin{abstract}
Statement of the problem: The emergence of Polyetheretherketone (PEEK) in prosthodontics and its use as a foundation for ceramic veenering restorations demand reassessment of shade match of final restoration.
\end{abstract}

Purpose: This study aimed to investigate the use of different foundation materials on the color output of two CAD/CAM lithium silicate ceramics.

Material and Methods: Rectangular plate specimens (60 samples) were prepared from CAD/ CAM generated all-ceramic materials of shade A2; IPS e.max (EM) CAD and Vita suprinity blocks (ZLS). A reflectance spectrophotometer used to measure the colour difference of ceramic samples before and after bonding to different foundation specimens; Zirconia (ZR), resin composite (RC), and PEEK; all of shade A2. The parameter of colour was measured via CIE L*a*b* (Commission Internationale de L'Eclairage) color system. Statistical analysis of data were done using two way ANOVA and the Tukey HSD test $(\alpha=0.05)$.

Results: ANOVA revealed that $\triangle \mathrm{E}$ values influenced significantly $(\mathrm{P}<.05)$ by the composition of ceramic material and different foundation materials used. However; the interaction was almost not statistically significant between the variables ( $\mathrm{p}=.294)$. In comparison to ZR and RC assemblies, the foundation material; PEEK, revealed comparable color parameters when assembled with each of the tested veneering material.

Conclusions: Zirconia reinforcement of CAD / CAM lithium silicate glass-ceramics decrease the impact of color variations on the various foundation materials used. The level of color acceptance varies between the ceramic and foundation materials tested. Compared to other widely used foundation materials (ZR and RC); PEEK displayed no different tendencies in color properties.

KEY WORDS: Lithium Silicate Ceramics, Color, PEEK, Foundation materials.

\footnotetext{
* Dental Biomaterial Department, Faculty of Dentistry, Tanta University, Tanta, Egypt.
} 


\section{INTRODUCTION}

Nowadays; one of the most challenging and complex universal demand in dentistry is the creation of a restoration with lifelike appearance. Therefore; all ceramic restorations gained the mastery in esthetic appearance over metal-ceramic restorations ${ }^{1}$.

A variety of all ceramic materials and manufacturing techniques emerging in the dental store. Computer-Aided Design (CAD) and Computer-Aided Manufacturing (CAM) has been emerging as an alternative to the traditional method of manufacturing. It became a gold standard in the field of dentistry ${ }^{2-6}$.

Lithium disilicate-reinforced glass-ceramics prosthesis combined the adequate strength properties, and adequate esthetic properties, which encourage its wide use in fixed restorations; veneers, multiple-unit posterior prostheses and dental implant restorations ${ }^{5-8}$. In the last few years Vita Suprinity was introduced in the market; where lithium silicate ceramic is reinforced with zirconium dioxide (ZLS) in an attempt to gain the required esthetic and strength properties ${ }^{9}$.

The final all ceramic restoration that have appropriate match with the corresponding shade guide is a multifactorial issue ${ }^{10-13}$. These factors include the type of ceramic material, steps of manufacturing (condensation technique, number of firing cycles and temperature, and ceramic thickness), and thickness of dentin remaining ${ }^{14-22}$.

Optical interaction between light and tooth structure is responsible for its color. Brightness, hue and chroma are the main optical parameters of tooth structure ${ }^{23-26}$. The underlying abutment and different foundation materials has a critical role in color production of all ceramic system in addition to their role in reinforcing the integrity and stability of the restoration ${ }^{27,28}$. Consequently; the dentist and dental technician should be aware about the final restoration color that match the selected shade guide is the net results of restoration materials color, abutment and foundation shade ${ }^{22,29}$. Therefore; different foundation materials used in restoring endodontically treated teeth in combination with all ceramic restorations may have a great impact on the color output of final restoration and should be deemed.

It has become clear that polyetheretherketone (PEEK) is a propitious and promising in prosthetic dentistry. PEEK is a linear, aromatic, semicrystalline thermoplastic polymer that has tremendous mechanical properties ${ }^{30}$. Stawarczyk et al. 2014 and Uhrenbacher et al. 2014 proved that PEEK has appropriate mechanical stability and it allows bonding to veneering materials $\mathrm{s}^{31,32}$. However, its low translucency and grayish or even snow-white color may have passive effect on the esthetic demands if it used as full coverage. Therefore; it may require the addition of resin composite or ceramic materials for veneering ${ }^{33}$. Few studies are available investigating the color characteristics and optical properties of PEEK in comparison with other popular foundation materials in conjunction with veneering materials.

This study was designed to assess the matching of the shade of CAD/CAM zirconia reinforced lithium silicate glass-ceramics compared to lithium disilicate glass ceramics veneered materials, when using various foundation materials; zirconia (ZR), resin composite $(\mathrm{RC})$ and PEEK. The hypothesis is that; there is no difference in the color of each tested veneering material when using any of various foundation materials.

\section{MATERIALS AND METHODS}

\section{Specimens preparation of veneering materials}

Sixty rectangular plate slice specimens (14 x 12 $\mathrm{x} 1 \mathrm{~mm}$ ) were prepared from Lithium disilicate glass ceramic (EM) (IPS e.max CAD; IvoclarVivadent) and zirconium dioxide reinforced lithium silicate 
ceramics (ZLS) (Suprinity, Vita Zahnfabrik) blocks in a pre-crystalline stage utilizing water cooled, slow speed diamond saw (Isomet, Buehler Ltd., Lake Bluff, IL). The manufacturers' instructions were followed during ceramic blocks crystallization. The surfaces of the specimens to be measured for color were finished using wet grit silicon carbide paper (\#400, \# 800 and \#1200). Then, for each specimen the thickness was verified using digital caliper (Electronic Digital Caliper, Shan, China). Finally, all specimens were cleaned for 10 min ultrasonically in distilled water.

\section{Fabrication of non-tooth color foundation}

The ceramic specimens were tested over three foundations; 20 test specimens each, The following foundation materials were prepared in a standardized dimensions $12 \times 14 \times 2 \mathrm{~mm}$ : zirconia (ZR), shade resin composite (RC), and PEEK. All the used veneering materias and those of the tested foundation ones were of shade A2.

The following CAD/CAM foundation materials: PEEK (Dentokeep; nt-trading, Karlsruhe, Germany), and $\mathrm{ZrO}_{2}$ (IPS e.max ZirCAD; Ivoclar Vivadent, Schaan, Liechtenstein) were cut into 2 mm thick rectangular slices. Then, $\mathrm{ZrO}_{2}$ specimens were sintered (LHT 02/16, Nabertherm GmbH, Lilienthal/Bremen, Germany) according to the manufacturer instructions at a heating rate of $10^{\circ} \mathrm{C} /$ min to $1500^{\circ} \mathrm{C}$ with a holding time of $120 \mathrm{~min}$.

Resin composite foundation samples were incrementally prepared with multiple layers of a nanofiber-reinforced hybrid resin composite (NovaPro Fill Universal; NANOVA Columbia MO. USA) using a plastic mold $12 \times 14 \times 2 \mathrm{~mm}$ and each increment polymerized for $40 \mathrm{~s}$. The specimens were covered by glass slab to obtain a smooth surface before polymerization. Finally; the resin samples were polished using 800 -grit silicon carbide abrasive papers.

\section{Color measurement of ceramic specimens before foundation bonding}

A computer-controlled reflectance spectrophotometer was conducted (UV-3101PC; Shimadzu, Japan) with integrated sphere attachment, D-65 light source, 360 and $720 \mathrm{~nm}$ range, and $10^{\circ}$ viewing angle for measuring of the color of ceramic specimens. $\mathrm{L}^{*}, \mathrm{a}^{*}$ and $\mathrm{b}^{*}$ color coordinates which characterize lightness, red-green chromaticity index and yellow-blue chromaticity index respectively, was specified from the transmittance and reflectance data using a computer software (X-rite; GmbH Optronic, Berlin, Germany).

\section{Bonding of ceramics-foundation disks assembly:}

Before cementation, the ceramic surfaces to be bonded were treated with $9.6 \%$ hydrofluoric acid (Porcelain etch, Pulpdent) for 20 seconds, rinsed with water and air dried. Ceramic primer (Monobond S; Ivoclar Vivadent) was applied for 60 seconds and air dried. Clear resin cement (Nexus NX3; Kerr Corporation) was used for bonding; photopolymerized for $40 \mathrm{~s}$ from each side. All specimens were kept under constant axial force until complete setting of the cement.

\section{Color measurement after bonding}

The color coordinates $\left(\mathrm{L}^{*}, \mathrm{a}^{*}\right.$ and $\left.\mathrm{b}^{*}\right)$ of each ceramic-foundation assembly were determined and the $\Delta \mathrm{E}$ (color difference) was calculated between the tested groups and subgroups by using the color difference formula:

$$
\Delta \mathrm{E}=\sqrt{\left(\Delta L^{*}\right)^{2}+\left(\Delta a^{*}\right)^{2}+\left(\Delta b^{*}\right)^{2}}
$$

Where:

$\Delta \mathrm{E}$ represent the total color difference, $\Delta \mathrm{L}^{*}$, $\Delta \mathrm{a}^{*}$ and $\Delta \mathrm{b}^{*}$ represent the difference of $\mathrm{L}^{*}, \mathrm{a}^{*}$ and $b^{*}$ of veneering ceramic materials before and after bonding to the foundation materials. 


\section{Measurement of the shade guide color properties}

The middle third part of shade A2 tab in shade guide (chromascop, Ivoclar Vivadent) was measured using the same condition as described before. $\mathrm{L}^{*}, \mathrm{a}^{*}$ and $\mathrm{b}^{*}$ was determined three times and the average was calculated.

\section{Statistical analysis}

The results were statistically analyzed using SPSS software 20.0 (SPSS Inc, Chicago, IL). To assess data homogeneity, the Levene test was used. Two-way analysis of variance (ANOVA) was used to analyze the data for significant differences in shade match recorded for the tested groups at the significance level of 0.05 , followed by Tukey HSD post hoc test at a $95 \%$ confidence level for multiple comparisons.

\section{RESULTS}

Table I presents the mean color co-ordinates values $\left(\mathrm{L}^{*}\right),\left(\mathrm{a}^{*}\right)$, and $\left(\mathrm{b}^{*}\right)$ of the ceramic test groups before bonding to foundation materials and those of A2 shade tab. There was a significant difference among $\mathrm{L}^{*}$ value of EM and ZLS and the shade guide $(\mathrm{P}<.05)$ before bonding to foundation blocks. $\mathrm{L}^{*}$ values of EM group was higher than ZLS group. Though the $a^{*}$ value of ZLS group was statistically higher than that of EM groups and shade guide. While the $b^{*}$ value of EM and ZLS groups were significantly lower than the shade guide.
TABLE (I) Means \pm standard deviations of the L*, $a^{*}$, and $b^{*}$ values of ceramic groups and the scale before bonding. Groups with the same letter are not statistically significant $(\mathrm{P}<0.05)$

\begin{tabular}{|c|c|c|c|}
\hline Groups & $\mathrm{L}^{*}$ & $\mathrm{a}^{*}$ & $\mathrm{~b}^{*}$ \\
\hline ZLS & $67.47 \pm 1.26^{\mathrm{a}}$ & $2.77 \pm 0.25^{\mathrm{d}}$ & $11.11 \pm 1.15^{\mathrm{g}}$ \\
\hline EM & $70.4 \pm 1.91^{\mathrm{b}}$ & $0.17 \pm 0.04^{\mathrm{e}}$ & $11.33 \pm 1.47^{\mathrm{g}}$ \\
\hline Scale & $77.42^{\mathrm{c}}$ & $0.1^{\mathrm{e}}$ & $18.7^{\mathrm{h}}$ \\
\hline
\end{tabular}

After Bonding to foundation blocks, the asseblies showed no significant difference of the mean values of $\triangle \mathrm{E}$ except for $\mathrm{ZR}$ and PEEK veneered by $\mathrm{EM}$. The lowest mean $\Delta \mathrm{E}$ value among all tested groups obtained with Suprinity bonded to $\mathrm{RC}$, while the highest one obtained with EM bonded to $\mathrm{ZR}$. In addition, when the $\left(\mathrm{L}^{*}\right)$ was evaluated for the bonded ceramic-foundation assembly; results indicated significant higher value of PEEK-EM than PEEK-ZLS assembly. While the a* value of ZLSfoundation assembly were statistically higher than that of corresponding EM- foundation assembly groups. Moreover, the $b^{*}$ value of ZR-EM groups was statistically differed from ZR- ZLS assemblies. (Table II).

The 2-way ANOVA indicated that the veneering ceramic material significantly influenced the $\Delta \mathrm{E}$ values, regardless the foundation materials used $(\mathrm{P}<.001)$ (Table III).

TABLE (II) Means \pm standard deviations of the $\mathrm{L}^{*}, \mathrm{a}^{*}, \mathrm{~b}^{*}$ and $\triangle \mathrm{E}$ values of EM and ZLS after bonding to foundation block. Groups with the same letter are not statistically significant $(\mathrm{P}<0.05)$.

\begin{tabular}{|c|c|c|c|c|c|}
\hline Groups & & $\mathrm{L}^{*}$ & $\mathrm{a}^{*}$ & $\mathrm{~b}^{*}$ & $\Delta \mathrm{E}$ \\
\hline ZLS & ZR & $68.30 \pm 0.81^{\mathrm{a}}$ & $2.89 \pm 0.2^{\mathrm{c}}$ & $11.49 \pm 1.1^{\mathrm{g}}$ & $1.47 \pm 0.85^{\mathrm{i}}$ \\
\hline & CR & $68.69 \pm 0.77^{\mathrm{a}}$ & $2.81 \pm 0.25^{\mathrm{c}}$ & $11.41 \pm 1.24^{\mathrm{g}}$ & $1.06 \pm 0.61^{\mathrm{i}}$ \\
\hline & PEEK & $68.62 \pm 1.06^{\mathrm{a}}$ & $3.04 \pm 0.32^{\mathrm{c}}$ & $12.07 \pm 1.16^{\mathrm{g}, \mathrm{h}}$ & $1.09 \pm 0.64^{\mathrm{i}}$ \\
\hline EM & ZR & $71.09 \pm 0.45^{\mathrm{a}, \mathrm{b}}$ & $1.33 \pm 0.92^{\mathrm{d}}$ & $13.58 \pm 0.25^{\mathrm{h}}$ & $2.67 \pm 0.75^{\mathrm{j}}$ \\
\hline & CR & $71.09 \pm 0.35^{\mathrm{a}, \mathrm{b}}$ & $0.75 \pm 0.56^{\mathrm{e}}$ & $12.83 \pm 0.54^{\mathrm{g}, \mathrm{h}}$ & $1.77 \pm 0.42^{\mathrm{i}}$ \\
\hline & PEEK & $72.43 \pm 2.63^{\mathrm{b}}$ & $-0.002 \pm 0.65^{\mathrm{f}}$ & $12.22 \pm 2.00^{\mathrm{g}}$ & $2.43 \pm 0.73^{\mathrm{j}}$ \\
\hline
\end{tabular}


TABLE (III) 2-way ANOVA analysis for the interaction of different variables on mean $\Delta \mathrm{E}$.

\begin{tabular}{|l|c|c|c|c|c|}
\hline \multicolumn{1}{|c|}{ Source } & Type III Sum of Squares & df & Mean Square & F & Sig. \\
\hline Corrected Model & $22.953^{\mathrm{a}}$ & 5 & 4.591 & 10.883 & .000 \\
\hline Intercept & 183.372 & 1 & 183.372 & 434.748 & .000 \\
\hline Ceramic & 17.535 & 1 & 17.535 & 41.573 & .000 \\
\hline After bonding to foundation & 4.361 & 2 & 2.181 & 5.170 & .009 \\
\hline Ceramic * after bonding to foundation & 1.057 & 2 & 0.528 & 1.252 & .294 \\
\hline Error & 22.777 & 54 & 0.422 & & \\
\hline Total & 229.102 & 60 & & & \\
\hline Corrected Total & 45.729 & 59 & & & \\
\hline
\end{tabular}

a. $R$ Squared $=.502($ Adjusted $R$ Squared $=.456)$

\section{DISCUSSION}

For the development of prosthetic materials in dentistry, color evaluation and shade determination are crucial requirements. Shade guides have been accustomed as a color matching method, because it is a cheaper and more practical method. However, spectrophotometers and colorimeters devices have become common in dental clinics due to their numerical expression of colors, standardization, and precision $^{34-37}$.

The thickness level of $1.0 \mathrm{~mm}$ is the minimal thickness of all ceramic restoration at cervical area 38,39. It was selected for EM and ZLS samples in the current study to test the interaction and effects of the foundation materials shade on the final colour production.

The A2 shade of either Vita Suprinity or IPS e.max CAD ceramics that used in the current study was chosen as it is one of the most prevalence tooth shade. This was in agreement with Elamin et al ${ }^{40}$ who screened central incisor shade of a study group whose age from 15-72 years and concluded that shade (A) appears in $78.5 \%$ of the patient. Moreover; a survey done by Alrifai and Alharby ${ }^{41}$ for different ethnic groups central incisors showed that $\mathrm{A} 2$ is one of the most common shade.
Niu et al ${ }^{42}$ reported that a white opaque resin cement should be used irrespective of its thickness to conceal the color resulting from the bonding of lithium disilicate glass ceramic to non-tooth colored foundations. The present study therefore used transparent resin cement to elucidate the effect of foundation materials on the final color.

Research interests are growing in the measurement of teeth and dental restorations color using various devices, particularly when new materials appear. This requires various confirmation thresholds determination and interaction of color of teeth and dental materials ${ }^{43}$. There are few studies that assesses the impact of PEEK as a foundation material on the color properties of final ceramic restoration. PEEK is gaining much interest in oral rehabilitation research, as PEEKbased materials are applied in removable and fixed partial denture technology in addition to polymethyl methacrylate (PMMA)-based and resin composite materials. Because of low rate of discoloration and improved mechanical properties, PEEK has been used as alternate to denture base resin materials and the ordinary and well-evaluated foundation materials $^{44-46}$.

In the current study, $\mathrm{L}^{*}$ value of A2 shade guide tab was significantly higher than that of ceramic 
samples before bonding to different foundation materials. This may be attributed to the thicker thickness of the tested shade guide than the ceramic specimen's thickness used in this study ${ }^{9}$.

The findings of this study showed that; the $\Delta \mathrm{E}$ values of ZLS - assembly groups were not affected statistically by different foundation materials used. Meanwhile, for EM- assembly groups; ZR and PEEK recorded insignificant $\Delta \mathrm{E}$ values but $\mathrm{RC}$ showed lower significant value comparble to those of ZLS- assemblies. While there was a significant change between PEEK bounded to either ZLS or EM and between ZR bonded to either ceramic veneering used. Therefore, in the current study, the type of ceramic veneering affected the final color of the restoration that appear obvious with PEEK and ZR foundation materials. On the other hand, by using $\mathrm{RC}$ foundation there was no significant color changes observed between the used veneering ceramic. Hence the hypothesis that; there was no difference in the color of each veneering material with using various foundations was rejected.

The results were attributed to variation in the optical properties of the ceramic materials which were influenced by its crystalline composition ${ }^{48}$. The findings of the present study were in agreement with that of Targut et al ${ }^{21}$ who stated that; the underlying color of abutment is one of the factors that governed the color difference $(\Delta \mathrm{E})$ of $\mathrm{CAD} / \mathrm{CAM}$ generated ceramic restoration.

Furthermore; the results of EM-foundation assembly were also consistent with Azer et al ${ }^{48}$ findings who stated that the color of the abutment tooth irrespective of the ceramic shade influence the overall selected color of the ceramic veneer. In addition to Stevenson $\mathrm{B}$ and Ibbetson $\mathrm{R}^{15}$ who revealed that the underlying foundations have a significant effect on the final color of the restorations because of the different degree of translucency of the ceramic veneer. Also, Stawarczyk et al ${ }^{33}$, who studied the spectrophotometric assessment of PEEK as a foundation material showed that the foundation and veneering material had a significant impact, which elucidates an inherent color difference in the different assemblies.

Based on the $\Delta \mathrm{E}$ values, clinical color matching can be assessed. The color difference is identifyed as "perfect" when the $\Delta \mathrm{E}$ value of two colors is 0 , "very good "when the value is $0.5-1.5$ units, $1-2$ is "good", 2-3.5 is "clinically noticeable" and more than 3.5 is "unacceptable". Average color differences greater than $1.0 \Delta \mathrm{E}$ are considered visually perceivable to the human eye and $3.5 \Delta \mathrm{E}$ are categorized as unacceptable for clinical use $\mathrm{e}^{47,49}$. The results of our study showed that ZLS CAD/CAM veneering the three foundation used provided very good color matching with mean $\Delta \mathrm{E}$ value ranged from $1.06-1.47$ and that of EM assemblies with mean $\Delta \mathrm{E}$ value ranged from 1.77- 2.67 is noticeable but clinically perceptible. Thus, both ZLS and EM assemblies are considered appropriate for clinical use.

Vita Suprinity assemblies (ZLS) had a statistically significant lower mean $\triangle \mathrm{E}$ value than IPS e.max CAD (EM). This proved that Vita Suprinity was less affected by the foundation color than IPS e.max CAD which suggested that Vita Suprinity has a greater intrinsic ability to mask the underlying structure color than IPS e.max CAD. These findings could be explained as the presence of a ceramic type capable of masking the foundation color influencing the optical properties of the samples. In the ceramic matrix, larger and irregular particles are integrated, hindering the transmission of light and favoring the dispersion of light, resulting in a decrease in translucency and an increase in ceramic opacity. The presence of particles slightly larger than the incident wavelength result in optimum reflection and opacity and causing a refraction degree different from the matrix where they are embedded ${ }^{25}$.

It is worthynoting that other possible shade variables, opaque or shaded cements are interested issues to be furtherly investigated. 


\section{CONCLUSIONS}

The following may be inferred within the limitation of this research; CAD / CAM Zirconia reinforcement lithium silicate glass-ceramics reduces the impact of color variations on the different foundation materials used. The level of color acceptance varies between the ceramic veneering and foundation materials tested; ZLS foundation assemblies showed the highest color matching followed by EM foundation. Compared to other widely used foundation materials (ZR and RC); PEEK demonstrates similarity with respect to the CIE L*a*b* system parameters of the assemblies and individual veneering material.

\section{REFERENCES}

1. Heffernan MJ, Aquilino SA, Diaz-Arnold AM, Haselton DR, Stanford CM, Vargas MA. Relative translucency of six allceramic systems. Part I: core materials. J Prosthet Dent. 2002; 88:4-9.

2. Conrad HJ, Seong WJ, Pesun IJ. Current ceramic materials and systems with clinical recommendations: a systematic review. J Prosthet Dent 2007; 98:389-404.

3. Al Ben Ali A, Kang K, Finkelman MD, Zandparsa R, Hirayama $\mathrm{H}$. The effect of variations in translucency and background on color differences in CAD/CAM lithium disilicate glass ceramics. J Prosthodont. 2014;23: 213-20.

4. Wiedhahn K. From blue to white: New high strength material for cerec -- IPS e.max CAD LT. Int J Comput Dent. 2007; 10:79-91.

5. Mously HA, Finkelman M, Zandparsa R, Hirayama H. Marginal and internal adaptation of ceramic crown restorations fabricated with $\mathrm{CAD} / \mathrm{CAM}$ technology and the heat-press technique. J Prosthet Dent. 2014; 112:249-56.

6. Nogueira AD, Della Bona A. The effect of a coupling medium on color and translucency of CAD-CAM ceramics. J Dent. 2013;41:e18-23.

7. Horwitz JC. Lithium disilicate: masking discolored teeth. Dent Today. 2011; 30:114, 116-7.

8. Kurbad A, Reichel K. CAD/CAM-manufactured restorations made of lithium disilicate glass ceramics. Int J Comput Dent. 2005; 8:337-48.

9. Saker S. Shade Match of cad/caM LithiuM SiLicate aLLceraMic reStorationS: effect of ceraMic thickneSS and nontooth coLored foundation E D J. 2016; 62: 1243-1250.
10. Chang J, Da Silva J, Sakai M, Kristiansen J, Nagai SI. The optical effect of composite luting cement on all ceramic crowns. J Dent 2009; 37:937-43.

11. De Azevedo Cubas GB, Camacho GB, Demarco FF, PereiraCenci T. The effect of luting agents and ceramic thickness on the color variation of different ceramic against a chro- matic background. Eur J Dent 2011: 245-52.

12. Barão VA, Gennari-Filho H, Goiato MC, dos Santos DM, Pesqueira AA. Factors to achieve aesthetics in all-ceramic restorations. J Craniofac Surg. 2010; 21:2007-12. Review.

13. Ghulman MA, Awad MA. Color variation between matched and fabricated shades of different ceramics. J Prosthodont. 2013; 22:472-7.

14. Denissen H, Dozic A, van Waas M, Feilzer A. Effects of 5 manipulative variables on the color of ceramics used for computer generated restorations. Quintessence Int 2007; 38:401-8.

15. Stevenson B, Ibbetson R. The effect of the substructure on the color of samples/restorations veneered with ceramic. J Dent 2010; 38:361-8.

16. Azer SS, Ayash GM, Johnston WM, Khalil MF, Rosenstiel SF. Effect of esthetic core shades on the final color of IPS Empress all-ceramic crowns. J Prosthet Dent 2006; 96:397-401.

17. Öngül D, Şermet B, Balkaya MC. Visual and instrumental evaluation of color match ability of 2 shade guides on a ceramic system. J Prosthet Dent 2012; 108:9-14.

18. Alqahtani MQ, Aljurais RM, Alshaafi MM. The effects of different shades of resin luting cement on the color of ceramic veneers. Dent Mater J 2012; 31:354-61.

19. Douglas RD, Steinhauer TJ, Wee AG. Intraoral determination of the tolerance of dentists for perceptibility and acceptability of shade mismatch. J Prosthet Dent 2007; 97: 200-8.

20. Barizon KT, Bergeron C, Vargas MA, Qian F, Cobb DS, Gratton DG, Geraldeli S. Ceramic materials for porcelain veneers: part II. Effect of material, shade, and thickness on translucency. J Prosthet Dent. 2014; 112:864-70.

21. Turgut S, Bagis B, Ayaz EA. Achieving the desired colour in discoloured teeth, using leucite-based CAD-CAM laminate systems. J Dent. 2014;42: 68-74.

22. Comlekoglu ME, Paken G, Tan F, Dundar-Comlekoglu M, Ozcan M, Akan E, et al. Evaluation of different thickness, die color, and resin cement shade for veneers of multilayered CAD/CAM blocks. J Prosthodont 2016; 25:563-9.

23. Chaiyabutr Y, Kois JC, LeBeau D, Nunokawa G. Effects of abutment color, cement color, and ceramic thickness on the 
resulting optical color of a CAD/ CAM glass-ceramic lithium disilicatereinforced crown. J Prosthet Dent 2011; 105:83-90.

24. Niu E, Agustin M, Douglas RD. Color match of machinable lithium disilicate ceramics: effects of foundation restoration. $\mathrm{J}$ Prosthet Dent. 2013; 110:501-9.

25. Volpato CA, Monteiro S Jr, de Andrada MC, Fredel MC, Petter CO. Optical influence of the type of illuminant, substrates and thickness of ceramic materials. Dent Mater. 2009; 25:87-93.

26. Shimada K, Nakazawa M, Kakehashi Y, Matsumura H. Influence of abutment materials on the resultant color of heat-pressed lithium disilicate ceramics. Dent Mater J. 2006; 25:20-5

27. Guess, P.C.; Att, W.; Strub, J.R. Zirconia in fixed implant prosthodontics. Clin Implant Dent Relat Res. 2012; 14: 633-645.

28. Sinmazisik, G.; Demirbas, B.; Tarcin, B. Influence of dentin and core porcelain thickness on the color of fully sintered zirconia ceramic restorations. J Prosthet Dent. 2014; 111: 142-149.

29. Kim BJ, Lee YK. Influence of the shade designation on the color difference between the same shade-designated resin composites by the brand. Dent Mater 2009; 25:1148-54.

30. Stawarczyk, B.; Beuer, F.; Wimmer, T.; Jahn, D.; Sener, B.; Roos, M.; Schmidlin, P.R. Polyetheretherketone-a suitable material for fixed dental prostheses? J Biomed Mater Res Part B Appl Biomater. 2013; 101: 1209-1216.

31. Stawarczyk, B.; Jordan, P.; Schmidlin, P.R.; Roos, M.; Eichberger, M.; Gernet, W.; Keul, C. PEEK surface treatment effects on tensile bond strength to veneering resins. J Prosthet Dent. 2014; 112: 1278-1288.

32. Uhrenbacher, J.; Schmidlin, P.R.; Keul, C.; Eichberger, M.; Roos, M.; Gernet, W.; Stawarczyk, B. The effect of surface modification on the retention strength of polyetheretherketone crowns adhesively bonded to dentin abutments. J Prosthet Dent. 2014; 112: 1489-1497.

33. Stawarczyk B,Schmid P, Roos M, Eichberger M and Schmidlin P. Spectrophotometric Evaluation of Polyetheretherketone (PEEK) as a Core Material and a Comparison with Gold Standard Core Materials. Materials. 2016; 9:491.

34. Douglas RD, Przybylska M. Predicting porcelain thickness required for dental shade matches. J Prosthet Dent 1999;82: 143-9.

35. Corciolani G, Vichi A, Louca C, Ferrari M. Color match of two different ceramic systems to selected shades of one shade guide. J Prosthet Dent. 2011; 105:171-6.
36. Barath VS, Faber FJ, Westland S, Niedermeier W. Spectrophotometric analysis of all-ceramic materials and their interaction with luting agents and different backgrounds. Adv Dent Res 2003;17: 55-60

37. Fasbinder DJ. Digital dentistry: innovation for restorative treatment. Compend Contin Educ Dent 2010; 31:2-11.

38. Vichi A, Ferrari M, Davidson CL. Influence of ceramic and cement thickness on the masking of various types of opaque posts. J of Prosthet Dent. 2000; 83:412-7.

39. Kilinc E, Antonson SA, Hardigan PC, Kesercioglu A. Resin cement color stability and its influence on the final shade of all-ceramics. J of Dent. 2011; 39:30-6.

40. Elamin H, Abubakr N, Ibrahim Y. Identifying the tooth shade in group of patients using Vita Easyshade. Eur J Dent. 2015; 9: 213-7.

41. Alrifai M, Alharby H. A comparison of anterior teeth color among Polish, Saudi and Taiwanese students of dentistry. 2016; 126:134-7.

42. Niu E, Agustin M, Douglas RD. Color match of machinable lithium disilicate ceramics: Effects of cement color and thickness. J Prosthet Dent. 2014; 111:42-50.

43. Chu S, Trushkowsky R, Paravina R. Dental color matching instruments and systems. Review of clinical and research aspects. J Dent. 2010; 38: e2-e16.

44. Najeeb S, Zafar S, Khurshid Z, and Siddiqui F. Applications of polyetheretherketone (PEEK) in oral implantology and prosthodontics. J Prosthodont Res. 2016; 60: 12-19.

45. Ayaz E, Durkan R, Koroglu A and Bagis B. Comparative effect of different polymerization techniques on residual monomer and hardness properties of PMMA-based denture resins. J. Appl Biomater Funct Mater. 2014; 30: 228-233.

46. Kumari R, Nagaraj H, Siddaraju K, and Poluri R. Evaluation of the Effect of Surface Polishing, Oral Beverages and Food Colorants on Color Stability and Surface Roughness of Nanocomposite Resins. J Int Oral Health. 2015; 7: 63-70.

47. Bagis B, Turgut S. Optical properties of current ceramics systems for laminate veneers. J Dent. 2013; Aug;41 Suppl 3:e24-30.

48. Azer S, Rosential SF, Seghi R, Johnston W. Effect of substrate shades on the color of ceramic laminate veneers. J of Prosthe Dent. 2011; 106:179-83.

49. Nakamura T, Saito O, Fuyikawa J, Ishigaki S. Influence of abutment substrate and ceramic thickness on the color of heatpresses ceramic crowns. J Oral Rehabil. 2002; 29:805-9. 